Gut, 1980, 21, 9-17

\title{
Gastric cancer detection in gastric ulcer disease
}

\author{
R A MOUNTFORD, P BROWN, P R SALMON, C ALVARENGA, \\ C S NEUMANN, AND A E READ
}

From the University Department of Medicine, Bristol Royal Infirmary, Bristol

SUMMARY A retrospective study has been performed of all cases of gastric ulcer diagnosed or investigated within the Endoscopy Unit of the Department of Medicine, Bristol, over a three year period (1974-76). The average length of follow-up was two years. Two hundred and sixty five cases of gastric ulcer were studied of which 37 proved to be malignant $(14 \%)$. Presenting complaints of anorexia, weight loss, nausea and/or vomiting, and multiple $(>3)$ symptoms, were commoner in the malignant ulcer group. Ulcer site and the presence of coexisting duodenal ulceration were largely unhelpful in deciding the status of an ulcer. Malignant ulcers tended to be large ( $>1 \mathrm{~cm}$ diameter). Radiology was highly unreliable in distinguishing benign from malignant ulcers. Visual inspection at endoscopy was more reliable, but associated with a tendency to over-diagnose malignancy. False positive biopsies were uncommon (two cases). Three cases of clinically unsuspected superficial gastric carcinoma were revealed. Repeated endoscopy and biopsy of all gastric ulcers until they are completely healed is advised.

This study was undertaken in the belief that the advent of flexible fibreoptic endoscopy has changed the way in which gastric ulcers should be investigated and managed, by permitting more accurate distinction of benign and malignant ulceration. Four questions were posed: (1) What proportion of gastric ulcers submitted to gastroscopy are malignant? (2) What features should heighten clinical suspicion of malignancy? (3) What are the relative merits of barium radiology, endoscopy, biopsy, and cytology in distinguishing benign and malignant ulceration? (4) Will aggressive investigation of gastric ulcer reveal superficial carcinomas in significant numbers?

Although the study was retrospective, during the period reported a specific investigation plan (see below) was recommended for all patients. One limitation was the difficulty of instituting such a plan when running a referral service.

\section{Methods}

SELECTION OF PATIENTS

The records were searched of all oesophago-gastroduodenoscopies performed within the Endoscopy Unit of the Department of Medicine, Bristol, during the period January 1974 to December 1976 inclusive, a total of 2265 . This task was facilitated by a punch card system ${ }^{1}$ upon which is stored, in coded form,

'Kalamazoo Business Systems.

Received for publication 27 July 1979 information regarding each examination undertaken. The cards are filed in temporal sequence. The hospital records were sought of all patients in whom gastric ulceration had been recorded as a finding at barium radiology or endoscopy. The barium studies were reviewed. A gastric ulcer was defined as a breach in the mucosa of the stomach greater than $2 \mathrm{~mm}$ in its smallest diameter, recorded at endoscopy or unequivocally shown on barium meal within three months of the period of study. Where possible confirmatory clinical evidence was sought in the hospital notes-for example, findings at operation. Two hundred and seventy eight patients fell within this definition. Follow-up information was solicited from the case histories and, where applicable, by direct inquiry to the medical attendant. In 265 cases reasonably complete clinical and follow-up information was available and these form the group reported.

BENIGN V. MALIGNANT GROUPS

Using all the information that was availableclinical, radiological, endoscopic, and histocytological - the cases were divided into benign and malignant ulcer groups. The mean period of followup was two years. In most cases the distinction was clear. Where available, the findings at microscopic examination of resected specimens was regarded as definitive. 


\section{DATA RECORDED}

The data which were recorded on all patients included sex, age at time of presentation (in patients with a past history of gastric ulceration, the age at referral during the period of study was taken), and the presenting symptom or symptoms. The location and diameter of each ulcer were recorded as accurately as possible (where multiple ulcers were present data on the largest were taken). Information regarding coexisting duodenal ulceration was sought. Relevant drugs and systemic diseases were noted. The reported findings at radiology, endoscopic inspection, biopsy, and cytology were recorded.

\section{RADIOLOGY}

All barium examinations resulted from routine clinical requests. Most were performed by the radiological staff of the United Bristol Hospital. No standard technique was employed. The double contrast bai ium meal (DCBM) technique was being introduced during the period of study but many examinations were of the classical type. The films were reviewed by one of us (R. A. M.) and form part of a separate study.

\section{ENDOSCOPY}

All examinations were performed by one of three trained endoscopists, using a forward viewing instrument ${ }^{2}$ supplemented by a lateral viewer ${ }^{3}$ when indicated.

Biopsies were performed by means of a Martin spiked forceps. In general at least six biopsies were taken from any gastric ulcer not actively bleeding or which had recently bled. These included one from each quadrant of the ulcer wall, one from the base and one from any adjacent suspicious fold. Biopsies were immediately fixed in formalin and examined by a pathologist with special experience in interpreting endoscopic biopsy material.

Cytological specimens were obtained by means of a sheathed cytology brush. Specimens were firmly brushed on to slides, air-dried, and sent for Giemsa staining and experienced cytological assessment.

\section{PLAN OF INVESTIGATION}

The plan of investigation was as follows. Apparently benign ulcers were submitted to biopsy and cytology wherever possible, and a recommendation made that repeat endoscopic examination be performed after one month's medical treatment. Absence of any evidence of healing at the second examination was taken as an indication to recommend surgery. Scars were biopsied and brushed. If healing was incomplete at one month, a further endoscopy was recommended

'ACMI F8 or Olympus GIFD2.

'ACMI F5 A or Olympus JFB2. after another interval of four weeks. Failure of complete healing after two months medical treatment was taken as an indication to recommend surgery.

\section{Results}

Of the 265 cases reported, 37 were considered to represent malignant ulcers, an overall incidence of $14 \%$.

In the benign ulcer group there was an equal sex incidence (118 males, 110 females). The malignant ulcers showed the anticipated male preponderance (29 males, eight females, $P<0.01$ ).

The age range was similar for the two groups and is shown in Fig. 1. In both the benign and malignant ulcer groups the commonest incidence was in the 65-70 years range. The mean age at presentation in the benign ulcer group was slightly younger (58.7 years) than the malignant ulcer group (62.9 years) but the difference was not statistically different.

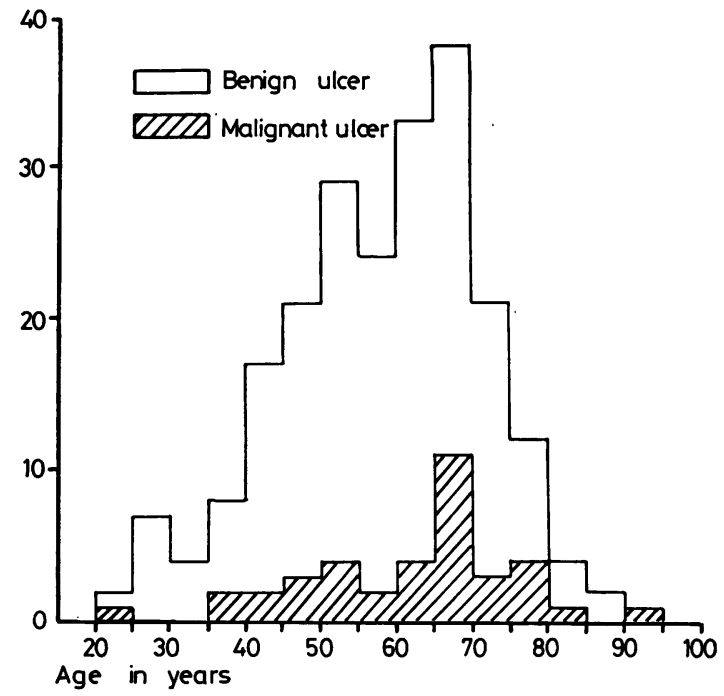

Fig. 1 Age at time of diagnosis of benign and malignant gastric ulcers.

The presenting clinical features were analysed for the two groups and are shown in Fig. 2. There were no significant differences between the two groups with respect to the two commonest presenting features. Thus $65 \%$ of the malignant ulcers and $75 \%$ of the benign ulcers presented with abdominal pain or dyspepsia, and the incidence of gastrointestinal bleeding or anaemia was $40 \%$ in both groups. The groups were discordant with respect to weight loss, anorexia, and nausea and/or vomiting. These symptoms were all commoner in the malignant ulcer group $(51 \%$ vs $19 \%, \mathrm{P}<0.0005 ; 30 \%$ vs $11 \%$, $\mathrm{P}<0.005$; and $41 \%$ vs $20 \%, \mathrm{P}<0.005$ respectively). 


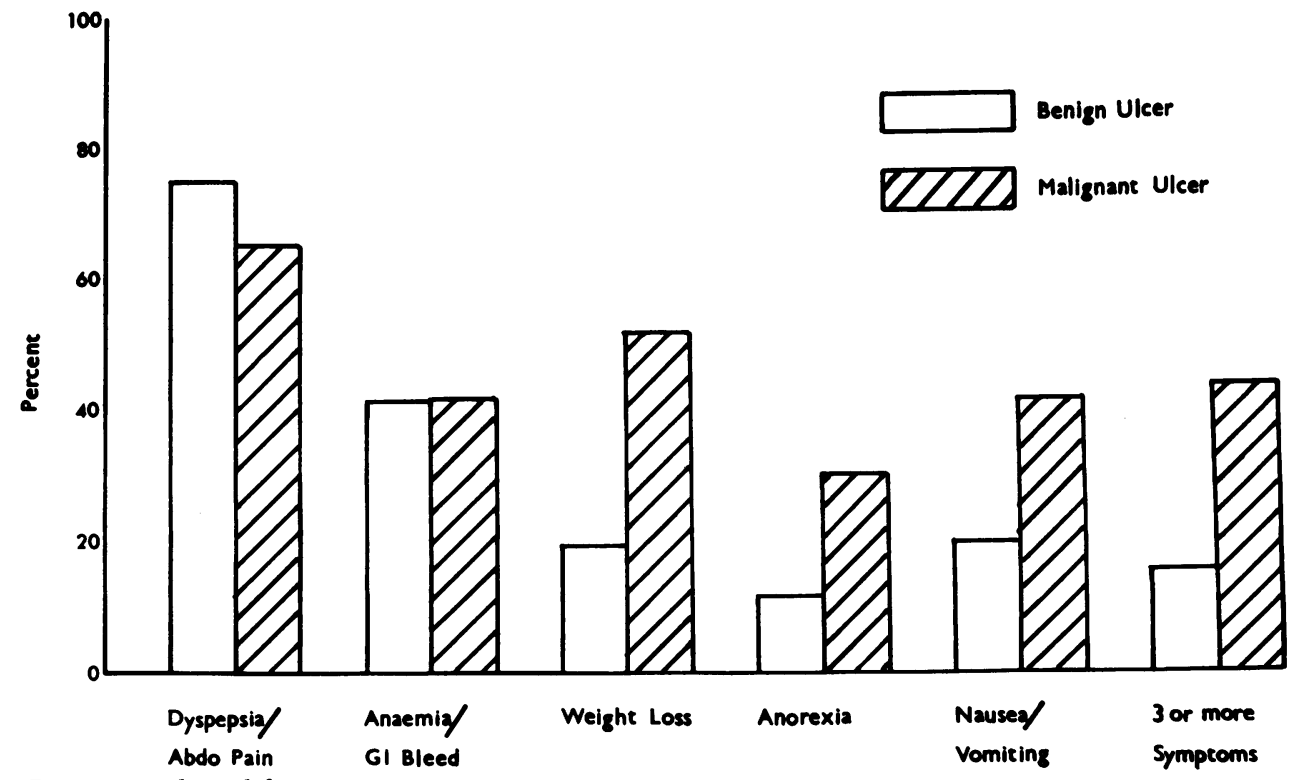

Fig. 2 Presenting clinical features.

In addition, in those patients with established gastric ulceration, multiple complaints (three or more of the above symptoms) were significantly commoner in the malignant ulcer group $(43 \%$ vs $15 \%, \mathrm{P}<0.0005)$.

The case notes were searched for evidence of coexisting disease and for a history of ingestion of drugs suspected of being associated with gastric ulceration. The results are shown in Table 1. It was

Table 1 Associated diseases or drugs

\begin{tabular}{lc}
\hline Group & No. \\
\hline Benign ulcer groups & \\
Gastric irritant drugs (for rheumatoid or & 18 \\
osteoarthritis) & 7 \\
Severe chronic obstructive airways disease & 2 \\
Steroids & 1 \\
Zollinger Ellison syndrome & 1 \\
Polycythaemia rubra vera & 1 \\
Malignant ulcer group & 1 \\
Severe chronic obstructive airways disease & \\
\hline
\end{tabular}

postulated that exposure to known ulcerogenic agents, or the presence of diseases associated with gastric ulceration might be taken as evidence of benign disease. However, the numbers are small and no statistically valid conclusions can be drawn from this.

The numbers of upper gastrointestinal endoscopies and barium meal examinations are shown in Fig. 3. As a consequence of the design of the study, the number of endoscopies parallels closely the incidence of gastric ulcer. There was perhaps some tendency for the number of barium investigations to diminish during the period of study. From the investigations plan outlined above, it was anticipated that several

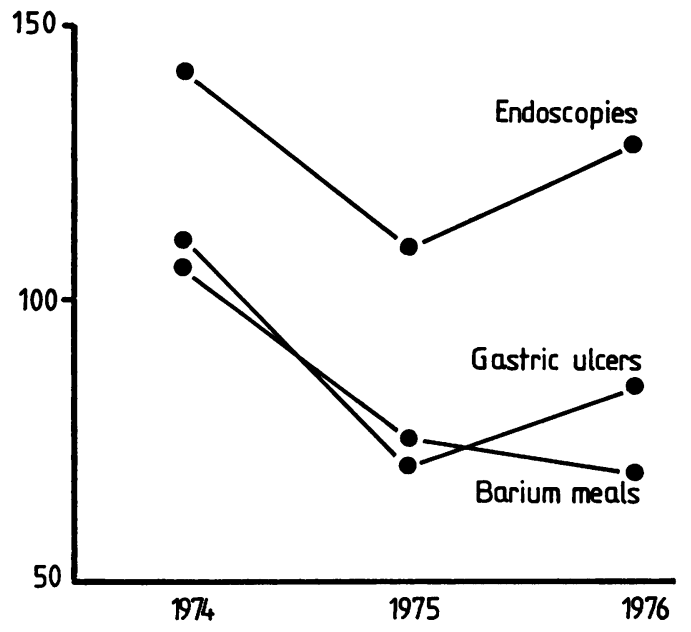

Fig. 3 Numbers of endoscopic and barium meal examinations performed on the study group during the period January 1974 to December 1976.

endoscopies would be performed on each benign gastric ulcer to check healing. In the event, the average number of endoscopies per case was 1.42. This was because the Endoscopy Unit offers a referral service and its recommendations are not necessarily followed.

Ulcer site and size were studied. The distribution of ulcers within the stomach is illustrated in Fig. 4. As expected, most ulcers occurred along the lesser curve, with a fair number in the pre-pyloric region. There was no evidence from this that greater curve ulcers are more likely to be malignant. Three 


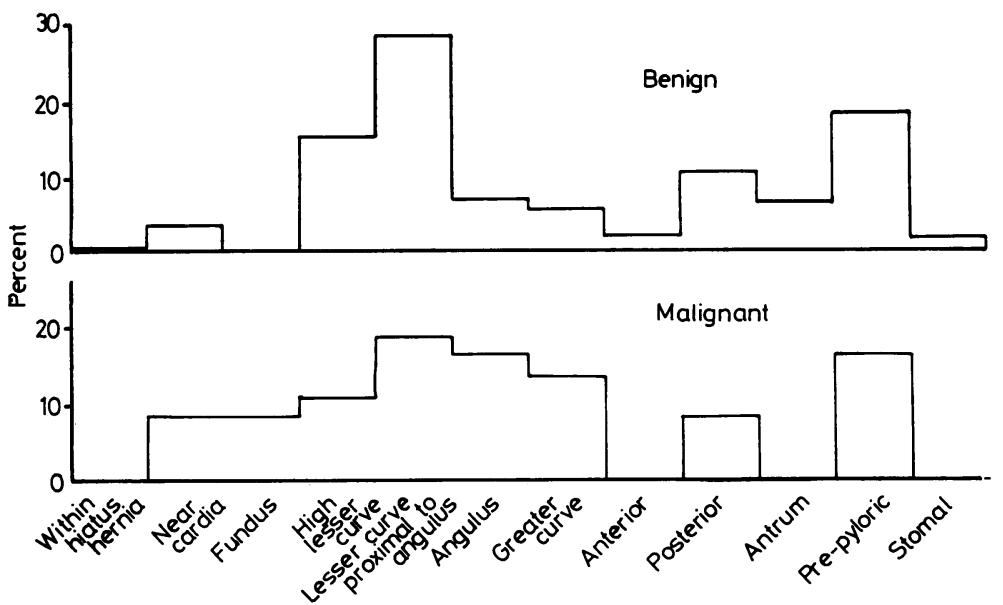

Fig. 4 Distribution of benign and malignant ulcers within the stomach.

malignant ulcers occurred in the fundus, whereas no benign ulcers were found in this site. This difference is significant $\left(\chi^{2}=18.5, \mathrm{P}<0.001\right)$.

Ulcer size is illustrated in Table 2. Data were not

Table 2 Diameter of ulcer

\begin{tabular}{lll}
\hline & Benign & Malignant \\
\hline $\begin{array}{l}\text { 'Small' ulcers } \\
\text { (Less than } 1 \mathrm{~cm} \text { in diameter) }\end{array}$ & 78 & 5 \\
'Large' ulcers & & \\
(1 cm or more in diameter) & 89 & 24
\end{tabular}

available in every case, but, where possible, ulcers smaller in diameter than $1 \mathrm{~cm}$ were distinguished from those of $1 \mathrm{~cm}$ or more across. There was a statistically significant difference between the groups $(\mathrm{P}<0.001)$, ulcers $1 \mathrm{~cm}$ or more in diameter being more likely to be malignant.

The data were examined for evidence of coexisting duodenal ulceration. Radiological and/or endoscopic evidence was sought of duodenal ulcer disease including a frank crater, duodenitis, or deformity of the bulb. One or more of these signs were present in association with both benign and malignant gastric ulceration in a high proportion of cases (Table 3) -

Table 3 Coexistent duodenal ulceration

\begin{tabular}{lcc}
\hline & $\begin{array}{l}\text { Benign ulcer } \\
\text { group }\end{array}$ & $\begin{array}{l}\text { Malignant ulcer } \\
\text { group }\end{array}$ \\
\hline Proven or suspected DU & 48 & 7 \\
No. DU & 180 & 30 \\
Totals & 228 & 37 \\
\hline
\end{tabular}

that is, $21 \%$ and $19 \%$ respectively. There was no significant difference statistically.

The various diagnostic procedures undertaken are considered separately for the malignant and benign ulcer groups.

MALIGNANT ULCERS

The results of barium meal examinations are shown in Table 4. These were included only where radiology had been performed within two months of definitive diagnosis (usually at endoscopy). This interval is

Table 4 Diagnostic parameters in malignant ulcer group

\begin{tabular}{|c|c|c|c|c|c|c|c|c|}
\hline & \multicolumn{2}{|c|}{ Radiology } & \multicolumn{2}{|c|}{ Endoscopy } & \multicolumn{2}{|c|}{ Biopsy } & \multicolumn{2}{|c|}{ Cytology } \\
\hline & (no.) & $(\%)$ & (no.) & $(\%)$ & (no.) & $(\%)$ & (no.) & $(\%)$ \\
\hline Benign & 3 & 8 & 1 & 3 & 9 & 24 & 8 & 22 \\
\hline Malignant & 8 & 22 & 29 & 78 & 24 & 65 & 6 & 16 \\
\hline Equivocal & 8 & 22 & 7 & 19 & - & & 1 & 3 \\
\hline Not performed & 10 & 27 & - & & 4 & 11 & 22 & 59 \\
\hline Not seen & 8 & 22 & - & & - & & - & \\
\hline Totals & 37 & & 37 & & 37 & & 37 & \\
\hline
\end{tabular}

rather long, but was chosen as a practical compromise. The eight cases in which radiology failed to show an ulcer might therefore be explained by resolution or development of an ulcer in the interval. Where a definite opinion as to the status of the ulcer was given, this was a correct statement of malignancy in eight, and an incorrect statement of benignancy in three. Thus, most of the cases in this study did not represent ulcerated carcinomas recognisable on radiology; there was considerable difficulty in deciding their status.

Visual inspection at endoscopy achieved better accuracy in diagnosing malignancy, as shown in Table 4. Thus only one was thought to be benign, whereas 29 were correctly stated to be malignant, or probably so.

One patient, who had previously undergone vagotomy and pyloroplasty, was endoscoped in 1973 and no lesion was seen. One year later a very extensive carcinoma was found, easily recognisable at barium meal and endoscopy. It seems likely that a lesion was missed at the original endoscopy.

Biopsy was positive in two-thirds of the group (Table 4).

Cytology was performed in only a minority of the cases (Table 4) because of technical difficulties, and 
was not positive in any patient in whom biopsy was negative. However, as cytology was performed in only 15 cases, firm conclusions cannot be drawn from this.

One case was originally missed by all methods of diagnosis. This patient presented in June 1973 with a lesser curve gastric ulcer demonstrated on barium meal (Fig. 5). Endoscopy was performed with

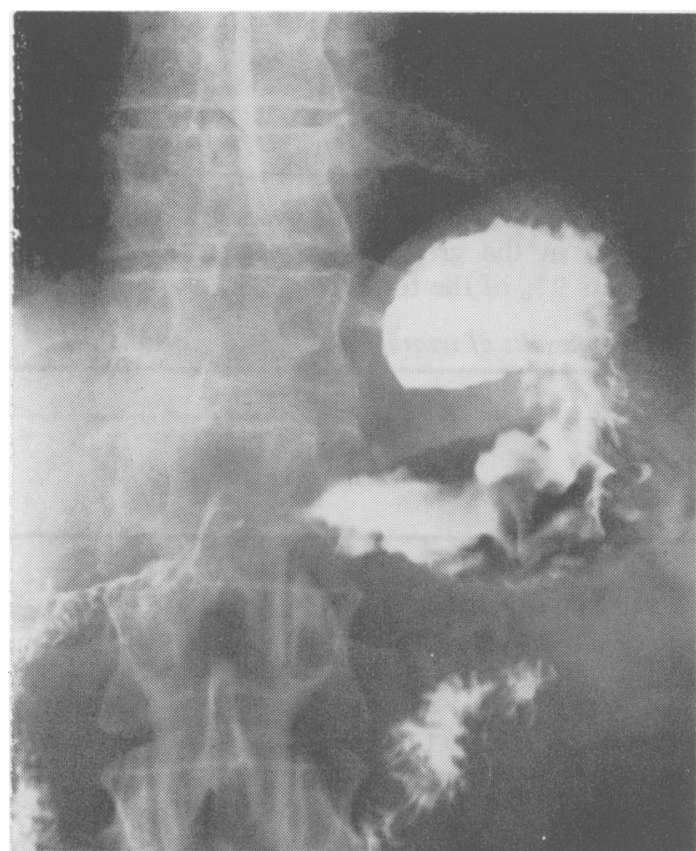

Fig. 5 Apparently benign gastric ulcer demonstrated on barium meal in June 1973.

multiple biopsies reported to show no malignant cells. The patient was treated conservatively and subsequently discharged. Two years later he returned with clinical features of gastric outflow obstruction (Fig. 6). Endoscopy and biopsy on this occasion revealed a stenosing antral carcinoma. Review of the original biopsy material revealed signet ring cells thought in retrospect to be clearly neoplastic.

The treatment undertaken in the malignant ulcer group is shown in Table 5. Fourteen cases were given either no therapy or symptomatic treatment only and have been placed in a 'palliative' category. In 23 some form of surgical resection was attempted. After an average follow-up of two years, only one patient in the 'palliative treatment' group was known to be alive (Table 6). Thirteen of the 23 cases in which radical resection was attempted were known to be dead. Five of these deaths were in the early (four weeks) postoperative period, which is to be expected in this group of elderly ill patients under-

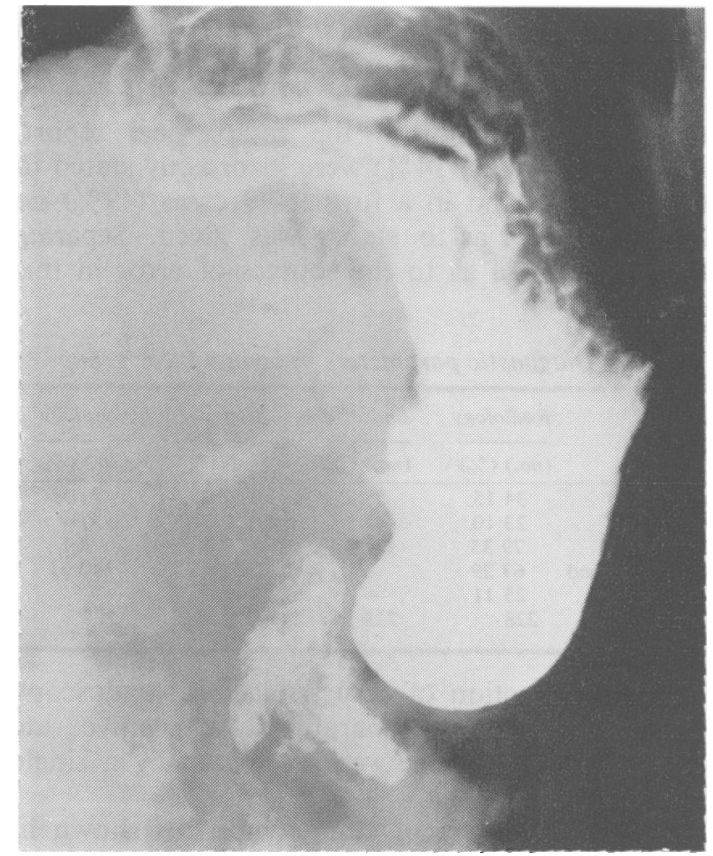

Fig. 6 Advanced annular carcinoma demonstrated in April 1975.

Table 5 Treatment of malignant ulcers

\begin{tabular}{lc}
\hline Treatment & no. \\
\hline 'Palliative' & 4 \\
None & 8 \\
Symptomatic only & 1 \\
HSV and ulcerectomy & 1 \\
Gastroenterostomy & \\
'Radical' & 10 \\
Partial gastrectomy & 7 \\
Subtotal gastrectomy & 6 \\
Total gastrectomy &
\end{tabular}

going major surgery for malignant disease.

The group of nine 'long-term' survivors after resection included three cases of superficial gastric carcinoma-that is, limited to within the muscularis propria. The patients were relatively young - 44 , 48, and 53 years-and at the time of follow-up had survived for 26,12 , and 16 months respectively, with no clinical evidence of recurrence.

BENIGN ULCERS

The results of radiological investigations are shown

Table 6 Results of treatment at two years' follow-up

\begin{tabular}{lccc}
\hline & 'Palliative' & 'Radical' & Totals \\
\hline Alive & 1 & 9 & 10 \\
Dead & 12 & $13^{*}$ & 25 \\
Lost to FU & 1 & 1 & 2 \\
& & & 37 \\
\hline
\end{tabular}

*Five early (1/12) postoperative deaths. 
in Table 7. Of the 161 cases in which radiology was performed within two months of definitive diagnosis $21 \%$ (34) of demonstrated ulcers were correctly stated to be benign in the radiological report. Howeves, 23 cases $(14 \%)$ were incorrectly stated to be malignant, and in a further 79 cases $(49 \%)$ no definite opinion as to status was given. Separate study is planned as to the sources of error in this material.

Table 7 Diagnostic parameters in benign ulcer group

\begin{tabular}{|c|c|c|c|c|}
\hline & Radiology & Endoscopy & Biopsy & Cytology \\
\hline & $($ no. $)(\%)$ & $($ no. $)(\%)$ & $(n o).(\%)$ & $($ no. $)(\%)$ \\
\hline Benign & 3415 & 5825 & 14463 & 8638 \\
\hline Malignant & 2310 & 4218 & 21 & $\mathbf{0}$ \\
\hline Equivocal & 7935 & 12856 & 73 & 21 \\
\hline Not performed & 6729 & - & 7533 & 14061 \\
\hline Not seen & 2511 & - & - & - \\
\hline Totals & 228 & 228 & 228 & 228 \\
\hline
\end{tabular}

Visual inspection of benign ulcers at endoscopy (Table 7) yields a comparable false positive rate $(18 \%)$. Many of these were examined by a single endoscopist.

Results of biopsy of benign ulcers is shown in Table 7. Two false positive results were obtained. One case was of a 69 year old man with a 10 year history of gastric ulceration. Barium meal and endoscopy showed a pre-pyloric ulcer with features suggestive of malignancy. Multiple biopsies were taken on three occasions, one of which was reported as containing adenocarcinoma. Cytology was consistently negative. At laparotomy the ulcer was thought to be benign. Biopsies were taken and a gastroenterostomy was performed. The operative specimens showed no evidence of malignancy and the patient has remained well on follow-up. Review of the endoscopic biopsy material revealed that the appearances had been misinterpreted.

The other case was that of a 72 year old man with lymphomatous involvement of the cardia and lower oesophagus. A gastric ulcer was present near the cardia and biopsies were said to show adenocarcinoma. At necropsy, six weeks after endoscopy, the gastric ulcer was benign, although there was widespread lymphomatosis elsewhere.

There were seven cases in which biopsy of benign gastric ulcers showed intestinal metaplasia with cellular atypia suspicious of malignancy. Most were submitted to surgery, but examination of operative specimens and careful follow-up has shown no evidence of overt malignancy. Table 7 shows that brush cytology was performed in relatively few cases. There were no false positives. In two cases suspicious cells were seen, but there was no evidence of malignancy on operative specimen follow-up.

The treatments that were used are shown in
Table 8. The drug regimes reflect medical fashion during the period studied. Operation was usually performed when suspicion of malignancy was raised

Table 8 Treatment of benign gastric ulcer

\begin{tabular}{lc}
\hline Treatment & $n o$. \\
\hline None & 28 \\
Antacids only & 31 \\
De-Nol & 15 \\
Caved S & 18 \\
Carbenoxolone & 57 \\
Cimetidine & 9 \\
Partial gastrectomy & 37 \\
Vagotomy & 33 \\
Total & 228 \\
\hline
\end{tabular}

on any of the diagnostic modalities discussed. Mortality in the group is shown in Table 9 and represents $9 \%$ of the total.

Table 9 Results of treatment of benign gastric ulcer

\begin{tabular}{lr}
\hline Outcome & no. \\
\hline Alive & 158 \\
Dead & 21 \\
Lost to follow-up & 49 \\
Total & 228 \\
\hline
\end{tabular}

\section{Discussion}

The findings will be considered in terms of the four questions posed at the beginning of the study.

\section{INCIDENCE OF MALIGNANCY}

The incidence of malignancy found in the present study $(14 \%)$ is much higher than in other reported series. Thus Darragh Montgomery and Richardson (1975) followed-up a series of 210 apparently benign gastric ulcers for a mean period of 5.7 years and discovered a total of 11 cancers $(5.0 \%)$. Similarly the Veterans' Administration's study (Grossmann, 1971) of 638 apparently benign gastric ulcers over seven years revealed 25 malignancies $(3.9 \%)$. Similar figures were given by Paustian et al. (1960) and Brown et al. (1961). Our patients were selected in that they were all referred for endoscopy. They included cases in which a gastric ulcer had previously been demonstrated at barium meal, and others in which endoscopy was requested as the initial investigation. However, of the 37 cases of cancer discovered, in only eight was there a firm radiological diagnosis of malignancy, before endoscopy. Thus 29 cases $(78 \%)$ came to endoscopy as the prime investigation to establish malignancy.

The high malignancy rate $(14 \%)$ is indicative of that likely to be found among the population of patients referred to an endoscopy clinic.

FEATURES INDICATIVE OF MALIGNANCY

The age of the patient is not helpful in deciding the 
status of a gastric ulcer. In this study there was a heavy male predominance in the malignant ulcer group which was not found with benign ulcers. Clinical features significantly more common in the malignant ulcer group were anorexia, weight loss, nausea and/or vomiting, and multiple symptoms. Grimes and Bell (1950) concluded that gastric malignancy could not be distinguished from benign ulceration on the basis of symptomatology. Other studies have shown a roughly equal frequency of epigastric pain, anorexia, weight loss, and bleeding in the two groups (Lampert et al., 1950; Gray and Ward, 1952). The former series showed more frequent and more marked weight loss in the cancer patients.

The site of the ulcer within the stomach was found to be unhelpful in deciding its status, with the possible exception of lesions within the fundus, which were exclusively malignant (three cases). This is broadly in line with the extensive Veterans' Administration study (Sun and Stempien, 1971) which concluded that there was no relationship between the location of an ulcer and the likelihood of it being malignant. The same Veterans' Administration series showed (Wenger et al., 1971), as does the present study, that malignant ulcers are likely to be large. The clinical value of this is limited, however, as, when faced with a large ulcer, the odds are still in favour of it being benign, all other things being equal, because malignant ulcers are relatively uncommon. It is widely held that the presence of coexisting duodenal ulceration reduces the chance that a gastric ulcer is malignant (Wilson et al., 1965; Rumball, 1971). This study failed to show this association, in common with that of Smith et al. (1953).

RELATIVE MERITS OF RADIOLOGY, ENDOSCOPY, BIOPSY, AND CYTOLOGY

The radiological signs of malignancy in gastric ulcers have been extensively reviewed (Gutman et al., 1939; Kirsh, 1971; Gabrielsson, 1972). Laing and Margulis (1974) claimed a $98 \%$ accuracy in distinguishing benign from gastric ulcers when certain recognised radiological signs were present. These authors stated that in most instances, radiographic distinction between a malignant ulcer and a benign ulcer is not difficult'. High degrees of accuracy have been claimed in studies of films reviewed 'blind' (Schulman and Simpkins, 1975). However, in unselected retrospective studies of benign and malignant ulcers, the reported routine radiological accuracies have been rather poor (Myren et al., 1975). Furthermore, as Nelson (1969) has pointed out, 'since most studies report that approximately $5 \%$ of gastric ulcers are malignant, our "accuracy" rate would be $95 \%$ if we diagnosed all of them as benign'.

Lesions may be missed altogether at radiology. Normal barium meals have been reported in $11-14 \%$ of patients with proven benign gastric ulcer and in $4-12 \%$ of patients with gastric cancer (Klotz et al., 1954; Templeton, 1955; Comfort et al., 1957). It seems likely that the double contrast barium meal permits more accurate distinction of benign and malignant gastric ulcers compared with single contrast techniques, but controlled trials are not available (Herlinger et al., 1977).

A test of healing has been widely canvassed (Wolf and Mophat, 1957), indicating that radiological evidence of resolution in response to medical treatment is proof of the benign nature of a gastric ulcer. This is no longer tenable in view of the work of Sakita et al. (1971), showing that $71 \%$ of malignant gastric ulcers undergo significant healing. They proposed a life cycle of ulceration, healing, and recurrent ulceration in association with malignancy.

Endoscopic inspection of gastric ulcers yields useful clues to diagnosis (Kidoko et al., 1963; Sakita, 1966). Gabrielsson's (1972) careful study of endoscopic signs showed eight which were helpful in distinguishing benign from malignant ulcers on visual inspection. All the above authors, however, emphasise that inspection is not entirely reliable and a tissue diagnosis is required. Thus Kobayashi et al. (1972) reported a series of 191 cases of superficial gastric carcinomas in which the initial diagnosis on endoscopic inspection was a benign ulcer in 35 $(18.3 \%)$ and of a benign lesion or inconclusive in $56(29 \cdot 4 \%)$. Histological and cytological diagnosis can be made with a high degree of accuracy, the two techniques being complementary to one another (Witte, 1970). Thus Kasugai (1970) claimed an accuracy in diagnosing early gastric cancer of $95 \%$ by gastric cytology, $96 \%$ by gastric biopsy and $97.9 \%$ by a combination of endoscopic techniques. Biopsy accuracy depends upon the number of biopsies performed (Kasugai and Kobayashi, 1974) with six biopsies being taken from the inside edge of the ulcer and from the ulcer base (Classen and Roesch, 1974).

The present study showed that there was perhaps some tendency locally for the number of barium meals requested to diminish over the period of study, in this particular diagnostic group. There was a disinclination for a firm radiological opinion to be given as to the status of any gastric ulcer demonstrated. Where an opinion was given as to the status of a demonstrated ulcer diagnostic accuracy was poor $(40 \%$ false positive rate, $27 \%$ false negative rate). The barium examinations were performed by many radiologists with varying experience and the 
double contrast technique was not used in all cases. Thus it is likely that diagnostic accuracy could be considerably improved. Barium radiology is likely to remain the prime investigative tool for patients with dyspepsia, for the foreseeable future. However, the present study would indicate that all gastric ulcers should be endoscoped and tissue obtained for a histological diagnosis by means of multiple biopsies and brush cytology. Histology was highly reliable in this series, although the number of negative biopsies obtained from malignant ulcers emphasises the need for multiple biopsies and serial examination. The correct management of the patient with severe cellular atypia on histology deserves further study.

\section{GASTRIC CANCER IN ASSOCIATION WITH ULCERATION}

Carcinoma of the stomach is a common disease accounting for approximately 15000 deaths in the British Isles annually, although this number is falling (Serial Mortality Tables, 1976). The prognosis in gastric carcinoma is poor and there is little evidence that it has improved over the years (Brookes et al., 1965). It is of interest in the present context that ulcer cancer has a better prognosis than gastric carcinoma in general (Olsson and Endresen, 1956; Runyeon and Hoerr, 1957).

Occasional cases of superficial gastric cancer have been reported in the past (Schade, 1958) but they did not arouse much clinical interest until Japanese workers reported large series of mucosal cancer detected by mass radiological or endoscopic screening (Kurokawa et al., 1967; Kawai, 1971). Surgical treatment of such patients results in a five year survival rate of $90 \%$ (Masuda, 1970). Increasingly, such cases are being diagnosed outside Japan (Ashby, 1974; Rösch and Thoma, 1974; Machado et al., 1976. Vilardell (1975) noted that 1195 superficial gastric cancers had been described in Europe over a five year period.

At least three clinical approaches to the diagnosis of superficial gastric carcinoma exist.

1. Screening of non-symptomatic patients. This is possible in Japan with an incidence approaching 1 in 2500 of the population but is not feasible in Europe and North America.

2. Patients with non-ulcer dyspepsia. The view that superficial carcinoma is asymptomatic is incorrect (Kawashiwa, 1966; Kurokawa et al., 1967; Rösch and Thorma, 1974). The relationship between dyspeptic symptoms, chronic atrophic gastritis, and superficial gastric carcinoma deserves further study.

3. Patients with gastric ulcer. The present study indicates that a fairly aggressive policy of investigation towards gastric ulcer will yield cases of super- ficial gastric cancer in about $1 \%$ of such patients. This is a fairly low incidence but these patients have an excellent prognosis after surgery and justify a policy of repeated endoscopy and biopsy until healing is complete in all gastric ulcers.

\section{References}

Ashby, B. S. (1974). Endoscopic diagnosis in advanced carcinoma of the stomach (Abstract). Gut, 15, 512.

Brookes, V. S., Waterhouse, J. A. H., and Powell, D. J. (1965). Carcinoma of the stomach: a 10-year survey of results and of factors affecting prognosis. British Medical Journal, 1, 1577-1583.

Brown, P. M., Cain, J. C., and Dockerty, M. B. (1961). Clinically 'benign' gastric ulcerations found to be malignant at operation. Surgery, Gynecology, and Obstetrics, 112, 82-88.

Classen, M., and Roesch, W. (1974). Gastroscopy, biopsy and cytology in early detection of stomach cancer. In Early Gastric Cancer. Current Status of Diagnosis, pp. 113-117. Edited by E. Grundmann, H. Grunze, and S. Witte. Springer-Verlag: Berlin.

Comfort, M. W., Priestley, J. T., Dockerty, M. B., Weber, H. M., Gage, R. P., Solis, J., and Epperson, D.P. (1957). The small benign and malignant gastric lesion. Surgery, Gynecology, and Obstetrics, 105, 435-448.

Darragh Montgomery, R., and Richardson, B. P. (1975). Gastric ulcer and cancer. Quarterly Journal of Medicine, 44, 591-599.

Gabrielsson, N. (1972). Benign and malignant gastric ulcers: evaluation of the differential diagnostics in roentgen examination and endoscopy. Endoscopy, 4, 73-83.

Gray, D. B., and Ward, G. E. (1952). Delay in diagnosis of carcinoma of the stomach. American Journal of Surgery, 83, 524-526.

Grimes, O. F., and Bell, H. G. (1950). Clinical and pathological studies of benign and malignant gastric ulcers. Surgery, Gynecology and Obstetrics, 90, 359-371.

Grossmann, M. I. (1971). Resume and comment. (Veterans Administration Cooperative Study on Gastric Ulcer). Gastroenterology, 61, 635-640.

Gutmann, R. A. (1971). On the early diagnosis of gastric cancer. American Journal of Gastroenterology, 56, 248-251.

Gutmann, R. A., Bertrand, I., and Péristiany, T. J. (1939). Le Cancer de l'Estomac au Début. Doin: Paris.

Herlinger, H., Glanville, J. N., and Kreel, L. (1977). An evaluation of the double contrast barium meal against endoscopy. Clinical Radiology, 28, 307-314.

Kasugai, T. (1970). Prognosis of early gastric cancer. Gastroenterology, 58, 429-431.

Kasugai, T., and Kobayashi, S. (1974). Evaluation of biopsy and cytology in the diagnosis of gastric ulcer. American Journal of Gastroenterology, 62, 199-203.

Kawai, K. (1971). Diagnosis of early gastric cancer. Endoscopy, 3, 23-27.

Kawashima, S. (1966). Early gastric cancer in Japan. Scandinavian Journal of Gastroenterology, 1, 248-252.

Kidoko, T. (1963). Diagnostic criteria by gastrocamera of 
early carcinoma of ulcer type. In Abstracts of the Fifth Annual Meeting of the Japanese Gastroenterological Endoscopy Society, pp. 46-48. Japanese Gastroenterological Endoscopy Society: Tokyo.

Kirsh, I. E. (1971). Cancer: Part II. Radiological aspects of cancer after apparent healing. (Veterans Administration Cooperative Study on Gastric Ulcer). Gastroenterology, 61, 606-621.

Klotz, A. P., Kirsner, J. B., and Palmer, W. L. (1954). An evaluation of gastroscopy. Gastroenterology, 27, 221-226.

Kobayashi S., Sugiura, H., and Kasagai, T. (1972). Reliability of endoscopic observation in diagnosis of early carcinoma of the stomach. Endoscopy, 4, 61-65.

Kurokawa, T., Kajitani, T., and Oota, K. (1967). Carcinoma of the Stomach in Early Phase. Nakayama: Tokyo.

Laing, F. C., and Margulis, A. R. (1974). Radiographic differentiation of benign and malignant gastric ulcers. Geriatrics, 29, 77-88.

Lampert, E. G., Waugh, J. M., and Dockerty, M. B. (1950). The incidence of malignancy in gastric ulcer believed pre-operatively to be benign. Surgery, Gynecology and Obstetrics, 91, 673-679.

Machado, G., Davies, J. D., Tudway, A. J. C., Salmon, P. R., and Read, A. E. (1976). Superficial carcinoma of the stomach. British Medical Journal, 2, 77-79.

Masuda, H. (1970). Zur Verbesserung der Prognose des Magenkarzinomes. Therapiewoche, 35, 1753.

Myren, J., Dybdahl, J., Serck-Hanssen, A., and Leitao, J. (1975). Gastroscopy with directed biopsy and routing $\mathrm{X}$-ray examination in the diagnosis of malignancies of the stomach. A retrospective study. Scandinavian Journal of Gastroenterology, 10, 193-197.

Nelson, S. W. (1969). The discovery of gastric ulcers and the differential diagnosis between benignancy and malignancy. Radiologic Clinics of North America, 7, 5-25.

Olsson, O., and Endresen, R. (1956). Ulcer cancer of the stomach. Acta Chirurgica Scandinavica, 3, 16-21.

Paustian, F. F., Stein, G. N., Young, J. F., Roth, J. L. A., and Bockus, H. L. (1960). The importance of the brief trial of rigid medical management in the diagnosis of benign versus malignant gastric ulcer. Gastroenterology, 38, 155-164.

Rösch, W., and Thoma, R. (1974). Anamnese beim Frühkarzinom des Magens. Medizinische Klinik, 69, 2063-2066.

Rumball, J. M. (1961). Co-existent duodenal ulcer.
(Veterans Administration Cooperative Study on Gastric Ulcer). Gastroenterology, 61, 622-627.

Runyeon, W. K., and Hoerr, S. O. (1957). The gastric ulcer problem: prognosis in masked malignancy. Gastroenterology, 32, 415-421.

Sakita, T. (1966). Endoscopic diagnosis. In Atlas of Early Carcinoma of the Stomach, pp. 224-228. Edited by M. Kuru. Nakayama: Tokyo.

Sakita, T., Ogurou, Y., Takasu, S., Fukutomi, H., Miwa, T., and Yoshimori, M. (1971). Observations on the healing of ulcerations in early gastric cancer. The life cycle of the malignant ulcer. Gastroenterology, 60, 835-844.

Schulman, A., and Simpkins, K. C. (1975). The accuracy of radiological diagnosis of benign, primarily and secondarily malignant gastric ulcers and their correlation with three simplified radiological types. Clinical Radiology, 26, 317-325.

Serial Mortality Tables (1976). Vols. 1-4. Deaths and death rates by sex, age, site and calendar period. Division of Epidemiology: Institute of Cancer Research, London.

Schade, R. O. K. (1958). Exfoliative cytology of gastric carcinoma. British Medical Journal, 1, 743-744.

Smith, F. H., Boles, R. S., Jr, and Jordan, S. M. (1953). Problem of the gastric ulcer reviewed: study of 1000 cases. Journal of the American Medical Association, 153, 1505-1508.

Sun, D. C. H., and Stempien, S. J. (1971). Site and size of the ulcer as determinants of outcome. (Veterans Administration Cooperative Study on Gastric Ulcer). Gastroenterology, 61, 576-584.

Templeton, F. E. (1955). Errors in diagnosis of gastric carcinoma. Gastroenterology, 28, 378-382.

Vilardell, F. (1975). Le diagnostic du cancer de l'estomac. Schweizer Medinizische Wochenschrift, 105, 556-559.

Wenger, J., Brandborg, L. L., and Spellman, F. A. (1971). Cancer: Part 1. Clinical aspects. (Veterans Administration Cooperative Study on Gastric Ulcer). Gastroenterology, 61, 598-605.

Wilson, W. J., Templeton, A. W., Turner, A. H., Jr., and Lodwick, G. S. (1965). The computer analysis and diagnosis of gastric ulcers. Radiology, 85, 1064-1073.

Witte, S. (1970). Gastroscopic cytology. Endoscopy, 2, 88-93.

Wolf, B. S., and Marshak, R. H. (1957). Profile features of benign gastric niches on roentgen examination. Journal of the Mount Sinai Hospital, New York, 24, 604-626. 